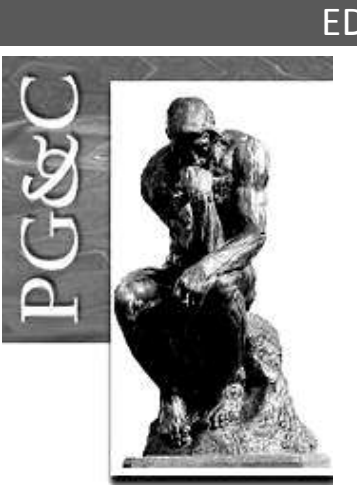

\title{
PERSPECTIVAS EM GESTÃO \& CONHECIMENTO: AGILIDADE NO FLUXO DA INFORMAÇÃO CIENTÍFICA
}

manteve periodicidade semestral, sem atrasar ou deixar de publicar qualquer edição.

A considerada demanda da PG\&C nos levou a aderir uma nova periodicidade, algo já registrado em nosso planejamento, com vistas à otimização da demanda e compromisso em fixar mais agilidade ao fluxo da informação científica.

Assim, o Volume 8, número 1, jan./abr. 2018 inaugura, com muita satisfação e sentimento de dever cumprido, a periodicidade quadrimestral da PG\&C, além de marcar um momento importante da história da revista.

A presente edição é composta por um Artigo de Revisão e nove Relatos de Pesquisa. Compõe-se, ainda, desse Editorial e do Expediente.

A seção Artigos de Revisão traz o artigo Memória organizacional, gestão do conhecimento e comportamentos de cidadania organizacional, de autoria de Paula Costa Neves e José Pedro Cerdeira. O artigo em questão aborda o conceito de memória organizacional como conhecimento organizacional que integra experiências passadas, arquivadas e vividas no contexto das organizações. Os autores chamam a atenção para a importância de preservar esta memória e para a necessidade de partilhar e manter o conhecimento dentro da organização, independentemente da rotatividade dos seus elementos.

A Seção Relatos de Pesquisa é iniciada pelo relato intitulado Criação do conhecimento organizacional baseada nos capacitadores de Von Krogh, Nonaka e Ichijo: estudo de caso, de autoria de Frederico Cesar Mafra Pereira e Elizângela Freitas da Silva, que se propôs a identificar e analisar quais capacitadores para a criação do conhecimento organizacional estão presentes numa empresa de Suinocultura localizada em Minas Gerais no Brasil, com base nas perspectivas de seus gestores e colaboradores.

O segundo Relato de Pesquisa, de autoria de Victor Fraile Sordi, Marina Keiko Nakayama e Erlaine Binotto, sob o título de Compartilhamento de conhecimento nas organizações: um modelo analítico sob a ótica da ação cooperativa propõe um modelo analítico e empírico do compartilhamento de conhecimento nas organizações norteado por uma abordagem do compartilhamento de conhecimento como ação cooperativa.

O Relato de Pesquisa Análise das principais lojas de comércio eletrônico do país sob a ótica do marketing digital nas redes sociais virtuais, de autoria de Monize Sâmara Visentini, Liara Laís Scheid e Fernanda Bad Chagas, considerando que a evolução do comércio eletrônico como canal de compras tem motivado as empresas virtuais a desenvolver estratégias competitivas, visa descrever as atividades desenvolvidas por reconhecidas empresas de comércio eletrônico dentro das fanpages do Facebook e identificar o engajamento dos usuários para com essas atividades desenvolvidas nas redes de relacionamento, assim como verificar quais atividades geram maior engajamento por parte dos clientes.

O quarto Relato de Pesquisa, de autoria de Roberto Bazanini, Ivonaldo Vicente da Silva, Homero Leoni Bazanini, Marcos Antônio Biff e Karina Rodrigues Negrão Mendes, intitulado Redes de relacionamento: a atuação dos stakeholders no mercado de bens simbólicos da educação busca investigar e analisar uma rede de relacionamento do mercado de bens simbólicos da educação tendo como objeto de pesquisa um grupo educacional situado na zona

Perspectivas em Gestão \& Conhecimento, João Pessoa, v. 8, n. 1, p. 1-3, jan./abr. 2018. DOI: http://dx.doi.org/10.21714/2236-417X2018v8n1p1.

http://periodicos.ufpb.br/ojs2/index.php/pgc. ISSN: 2236-417X. Publicação sob Licença (cc) EY-NC-ND. 
leste da cidade de São Paulo no Brasil.

Em seguida, o quinto Relato de Pesquisa, Proposta de planejamento para o setor lácteo no Rio Grande do Sul dos autores Henrique Dias Blois, Aliston de Oliveira Rothen, Maitê Peres de Carvalho e Bruno Blois Nunes, que tem como objetivo, a partir da teoria de prospecção de cenários, apresentar um planejamento estratégico com previsão de cinco anos para uma empresa do setor lácteo localizada em um município do Rio Grande do Sul.

Políticas de gestão de acervos: possíveis fontes de informação para tomada de decisão nos museus é o sexto Relato de Pesquisa. Nele as autoras Raquel França Garcia Augustin e Cátia Rodrigues Barbosa analisam as políticas de gestão de acervo disponibilizadas via web pelo Museu de Astronomia e Ciências Afins, Fundação Joaquim Nabuco, Casa de Oswaldo Cruz e Museu Paraense Emilio Goeldi como diretrizes para a tomada de decisão relacionada à preservação do patrimônio musealizado.

O Relato de Pesquisa Aplicação de competências científicas no trabalho: um estudo no Banco do Brasil, de autoria de Gerson Padilha de Almeida, Isa Aparecida de Freitas e Edilson Ferneda, verifica a aplicação de competências adquiridas por meio de um programa de capacitação de profissionais em nível de mestrado e doutorado de uma empresa que investe nesse tipo de capacitação de alto nível.

Em sequência o Relato de Pesquisa de autoria de Débora Gomes de Araújo e Guilherme Ataíde Dias, intitulado Contribuições de educação a distância na aprendizagem das organizações: um estudo na Universidade Federal da Paraíba analisa de que forma os cursos na modalidade a distância promovem aprendizagem em uma instituição de ensino superior, a partir da percepção dos servidores técnico-administrativos da instituição.

O último Relato de Pesquisa é de Henrique César Melo Ribeiro e Rosane Corrêa. Tem como título Revista Ibero-americana de estratégia: produção acadêmica de 2002 a 2015. Os autores realizam estudo bibliométrico de modo a investigar a representatividade e as particularidades da produção acadêmica divulgada pela Revista Ibero-Americana de Estratégia.

As contribuições aqui publicadas se envolvem diretamente com o foco e escopo da PG\&C. O resultado é uma produção científica proveniente de reconhecidos estudiosos, ao que apresentamos os agradecimentos por elegerem o periódico para veicular o vosso produto intelectual.

Convidamos todos para acessar os itens de interesse e para seguir a PG\&C no Twitter.

João Pessoa, Paraíba, Brasil, 30 de Abril de 2018.

Os Editores

Luciana Ferreira da Costa e Jorge de Oliveira Gomes

https://twitter.com/revistapgecufpb

Perspectivas em Gestão \& Conhecimento, João Pessoa, v. 8, n. 1, p. 1-2, jan./abr. 2018. 